\title{
A COMPARATIVE STUDY ON SAFETY AND EFFICACY OF MIDAZOLAM BY INTRANASAL AND INTRAVENOUS ROUTE FOR PAEDIATRIC PROCEDURAL SEDATION
}

\author{
Mohankumar M K' Shahana Jasmine Pyarajan ${ }^{2}$
}

1 Professor, Department of Paediatrics, Medical College, Calicut, Kerala, India.

2Junior Resident, Department of Paediatrics, Medical College, Calicut, Kerala, India.

ABSTRACT

\section{BACKGROUND}

Pain perception in young children did not receive much attention as there are concerns regarding the safety of administering potent opiates and sedatives. Moreover, we often consider that it is natural for children to cry in such situations and young children won't complain about pain. Midazolam is a short-acting benzodiazepine with rapid onset of action and is one of the most widely used sedatives in intensive care unit. The intranasal route avoids the need for intravenous access, avoids the pain of the parenteral injection, and is easily accessible for drug administration. The aim of this study is to compare the safety and efficacy of intranasal midazolam against intravenous midazolam for paediatric procedural sedation.

\section{MATERIALS AND METHODS}

This prospective study was conducted in Paediatric ward, IMCH, Medical College, Kozhikode from June 2015 to May 2016.128 children between 3 and 12 years requiring a diagnostic lumbar puncture were included. They were divided into 2 groups A (Intranasal) and B (Intravenous) by random allocation. Statistical analysis was performed using statistical package for social sciences 16.0 (SPSS 16.0) statistics analysing software.

\section{RESULTS}

The deviation of heart rate from baseline during procedure is significantly more in intravenous group with $\mathrm{t}(116.345)=2.354, \mathrm{p}=$ 0.020 \& also the deviation of heart rate from baseline at the end of procedure was significantly higher among intravenous group with $\mathrm{t}(103.974)=4.593, \mathrm{p}=0.000$. The deviation of diastolic blood pressure during procedure from baseline is significantly higher among the intravenous group with $\mathrm{t}(102.521)=4.535, \mathrm{p}=0.000 \&$ also the deviation of diastolic blood pressure from baseline to the end of procedure was significantly higher among the intravenous group with $\mathrm{t}(126)=4.819, \mathrm{p}=0.000$. The sedation achieved during the procedure is comparable between the two groups with a p value of 0.225 . The intranasal group took longer time to achieve adequate sedation as well as for recovery. But there were no serious adverse effects.

\section{CONCLUSION}

Intranasal midazolam is safe and effective for paediatric procedural sedation and is associated with lesser variability in heart rate and blood pressure in comparison with intravenous midazolam.

\section{KEY WORDS}

Midazolam, Intranasal, Intravenous

HOW TO CITE THIS ARTICLE: Mohankumar MK, Pyarajan SJ. A Comparative Study On Safety And Efficacy Of Midazolam By Intranasal \& Intravenous Route For Paediatric Procedural Sedation. J. Evolution Med. Dent. Sci. 2019;8(10):728-732, DOI: $10.14260 /$ jemds/2019/160

\section{BACKGROUND}

Everyone has one's own perception of pain. One of the important responsibilities of physicians caring for children is to eliminate or assuage pain and suffering whenever possible in the best way. But the truth is that in this regard a substantial percentage of children are under- treated.[1] The most common type of pain experienced by children is acute pain resulting from injury, illness, and in many cases, necessary medical procedures. ${ }^{[2]}$ Premedication is an integral component in the practice of paediatric anaesthesia. Fear of painful or unpleasant procedures and separation from parents will cause untoward psychological effects.

'Financial or Other Competing Interest': None.

Submission 28-06-2018, Peer Review 24-02-2019,

Acceptance 02-03-2019, Published 11-03-2019.

Corresponding Author:

Dr. Shahana Jasmine Pyarajan,

Pediatrician, ESI Hospital,

Olarikkara Pullazhi P. O.,

Thrissur-680012, Kerala, India.

E-mail: drshahanajasmine@gmail.com

DOI: $10.14260 /$ jemds $/ 2019 / 160$

\section{(c) $(7)(-$}

Pain perception in young infants and newborns did not receive much attention as there are concerns regarding the safety of administering potent opiates and sedatives to them due to the risk of resultant airway compromise and respiratory depression. Moreover, we often consider that it is natural for children to cry in such situations. [3] Effective pain management is every child's right. All the necessary peripheral and central nervous system anatomic structures and functional ability to process pain will be present by 20 weeks' gestation. [1]

Painful procedures that are usually performed outside the operating room are bone marrow aspiration, lumbar puncture, repair of minor surgical wounds, insertion of arterial and venous cannula and catheters, burns dressing changes, fracture reduction, bronchoscopy and endoscopy.[3] The development of newer pharmacologic agents and noninvasive monitoring techniques made it possible to administer effective short acting sedatives without compromising patient safety.

Midazolam is a short-acting benzodiazepine with rapid onset of action. It has anxiolytic, muscle relaxant properties and is one of the most widely used sedatives in the neonatal 
intensive care unit. For sedation, Young and Neofax [4,5] suggested giving $0.15 \mathrm{mg} / \mathrm{kg}$ midazolam intravenously, and $0.3 \mathrm{mg} / \mathrm{kg}$ for intranasal administration. When minimal sedation is required, intranasal midazolam is an excellent sedative.[6] Intranasal route have the potential for successful sedation with minimal risk. The intranasal route avoids the need for intravenous access, avoids the pain of the parenteral injection, and is easily accessible for drug administration. Due to the rich vascular plexus of the nasal cavity and the communication to the subarachnoid space via the olfactory nerve and sheath, adequate cerebrospinal fluid levels can be achieved rapidly. The bioavailability of intranasal midazolam ranged from $50 \%$ to $83 \%{ }^{[7]}$ The most common adverse effects reported following intranasal midazolam were burning or irritation in the nose and a bitter taste in the mouth.[8] Non parenteral administration of Midazolam is associated with equivalent safety and sedation profile as parenteral drug administration.

The aim of this study was to evaluate and compare the safety and effectiveness of midazolam by intravenous and intranasal route for procedural sedation in children and to assess the sedation by using validated scales.

\section{MATERIALS AND METHODS}

This prospective interventional study was conducted in Paediatric ward, IMCH, Medical College, Kozhikode from June 2015 to May 2016. Children between 3 and 12 years requiring a diagnostic Lumbar Puncture were divided into 2 groups A and B. Group A was given Intra nasal Midazolam and Group B was given Intravenous Midazolam.

Sample size was calculated using population survey method. It was found from the records of the paediatric wards that the children undergoing the diagnostic lumbar puncture as 75 per year. By taking 95\% confidence interval and $50 \%$ response rate and with $80 \%$ power, the sample size was found to be 64 .

Children between 3 and 12 years belonging to the physical status class 1 and class 2 as defined by American Society of Anaesthesiologist (ASA) in whom a diagnostic Lumbar Puncture is indicated were included. Children with difficulty in securing airway, upper respiratory tract infection, chronic illness involving cardiac, respiratory, liver and renal diseases, with previous history of Lumbar Puncture, intellectual disability and who had received a sedation within four hours of procedure were excluded. After an informed written consent from parents the children were randomly allocated into 2 groups A and B. Pre sedation evaluation including fasting guidelines, all necessary airway management and resuscitation equipment and vitals monitoring equipment were kept ready. Dermal analgesia at lumbar puncture site was achieved with EMLA cream 30 minutes before the procedure. Group A were given $0.3 \mathrm{mg} / \mathrm{kg}$ of Midazolam intra nasally, while group B were given 0.15 $\mathrm{mg} / \mathrm{kg}$ of Midazolam intravenously. Lumbar puncture (LP) was done using 23G 1.5-inch needle. The sedation timings, pulse rate, respiratory rate, blood pressure, SPO2 were recorded before drug administration and at 5 minutes interval until procedure ends and then at 10 minutes interval until child fulfils discharge criteria from procedure room by an independent observer.
Statistical analysis was performed using statistical package for social sciences 16.0 (SPSS16.0) statistics analysing software. To compare between means of the two groups independent sample t test is used and for comparing qualitative variables Chi square test is used. A p value less than 0.05 is taken as significant

This study was cleared by hospital ethical committee. There was no financial or other competing interest

\section{RESULTS}
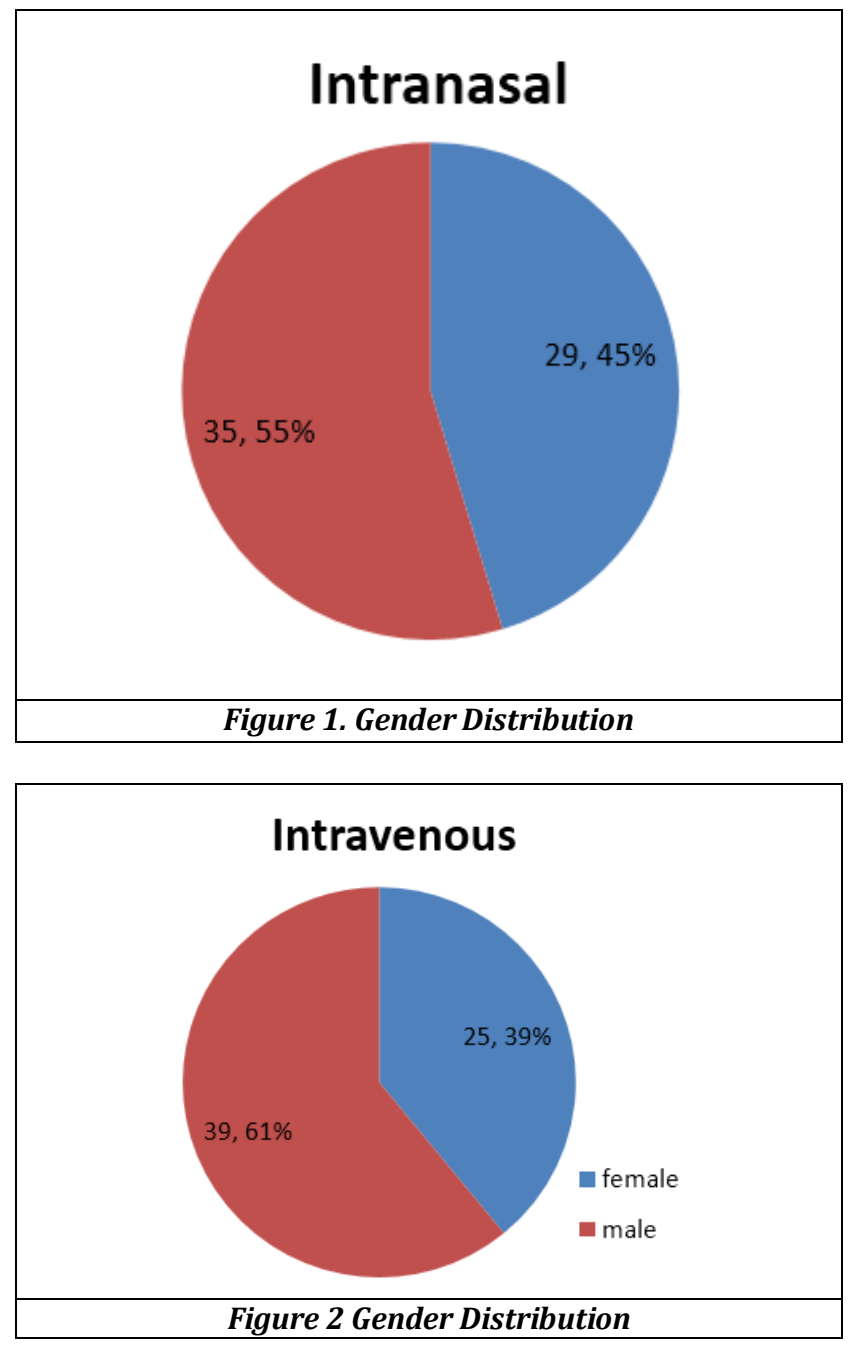

\begin{tabular}{|c|c|c|c|}
\hline & \multicolumn{2}{|c|}{ Gender } & Total \\
\hline & Female & Male & \\
\hline Intranasal & 29 & 35 & 64 \\
Intravenous & 25 & 39 & 64 \\
\hline Total & $\mathbf{5 4}$ & $\mathbf{7 4}$ & $\mathbf{1 2 8}$ \\
\hline$X^{2}$ value: 0.513, p-value: 0.474 . When the gender distribution \\
was analysed, it was found to be statistically not significant \\
with a p-value of 0.474. Hence the gender distribution is \\
comparable between the two groups and it is not affecting the \\
results. \\
\hline
\end{tabular}

\section{Comparison Between the Two Groups}

The means of variables between the two groups are tested with independent samples t-test and homogeneity of variances of the two groups is tested with Levene's test. The results are calculated with $95 \%$ confidence interval. 


\begin{tabular}{|c|c|c|c|c|}
\hline Group & Mean & Std. Deviation & t & p \\
\hline Intranasal & 97.06 & 13.548 & & \\
\cline { 1 - 3 } Intravenous & 94.12 & 10.152 & -1.388 & 0.168 \\
\hline
\end{tabular}

Comparison of Mean Baseline Heart Rate in Group A \& B The mean baseline heart rate in intranasal group was found to be slightly higher than intravenous group. But on doing independent samples t-test, it is found that the difference is not statistically significant with $\mathrm{t}(116.79)=-1.388, \mathrm{p}=0.168$.

\begin{tabular}{|c|c|c|c|c|}
\hline Groups & Mean & Std. Deviation & t & p \\
\hline Intranasal & 10.3438 & 7.85831 & & \\
\hline Intravenous & 14.2188 & 10.57020 & 2.354 & 0.020 \\
\hline Comparison of Means of Deviation in Heart Rate During \\
Procedure from Baseline \\
\hline \\
The deviation of heart rate from baseline during procedure is \\
significantly more in intravenous group with t (116.345) \\
$=2.354, \mathrm{p}=0.020$ \\
\hline
\end{tabular}

\begin{tabular}{|c|c|c|c|c|}
\hline Groups & Mean & Std. Deviation & t & p \\
\hline Intranasal & 12.7031 & 8.32796 & & \\
\cline { 1 - 1 } Intravenous & 21.9062 & 13.69824 & 4.593 & 0.000 \\
\hline \multicolumn{3}{|c|}{ Comparison of Means of Deviation in Heart Rate from } \\
Baseline to The End of Procedure \\
\hline \\
The deviation of heart rate from baseline at the end of \\
procedure was significantly higher among intravenous group \\
with t (103.974) $=4.593, \mathrm{p}=0.000$ \\
\hline
\end{tabular}

\begin{tabular}{|c|c|c|c|c|c|}
\hline & Group & Mean & Std. Deviation & t & p \\
\hline \multirow{2}{*}{ SBP } & Intranasal & 106.84 & 9.887 & & \\
\cline { 2 - 5 } & Intravenous & 106.66 & 8.980 & 0.112 & 0.911 \\
\hline \multirow{2}{*}{ DBP } & Intranasal & 76.16 & 7.201 & & \\
\cline { 2 - 4 } & Intravenous & 79.09 & 4.407 & 2.784 & 0.006 \\
\hline
\end{tabular}

Comparison of Mean Baseline Systolic and Diastolic Blood Pressures in Group $A$ \& B

The mean baseline systolic blood pressure (SBP) was found to be comparable between both the groups applying t-test. [t $(124.851)=-0.112, \mathrm{p}=0.911]$

But the mean baseline diastolic blood pressure in intravenous group was found to be higher than the intranasal group with statistical significance. [ $\mathrm{t}(126)=2.784, \mathrm{p}=0.006$ ]

\begin{tabular}{|c|c|c|c|c|c|}
\hline & Groups & Mean & Std. Deviation & $\mathbf{t}$ & p \\
\hline \multirow{2}{*}{$\begin{array}{c}\text { SBP } \\
\text { Difference }\end{array}$} & Intranasal & 7.8438 & 7.16521 & \multirow{2}{*}{0.587} & \multirow{2}{*}{0.558} \\
\hline & Intravenous & 7.1562 & 6.03487 & & \\
\hline \multirow{2}{*}{$\begin{array}{c}\text { DBP } \\
\text { Difference }\end{array}$} & Intranasal & 3.9062 & 3.82854 & \multirow{2}{*}{4.535} & \multirow{2}{*}{0.000} \\
\hline & ntravenous & 8.1562 & 6.44690 & & \\
\hline
\end{tabular}

\section{Comparison of Means of Deviation of SBP and DBP During} Procedure from Baseline

It is found that there is no significant difference among the two groups on comparing the means of deviation of SBP from baseline SBP with $\mathrm{t}(126)=-0.587, \mathrm{p}=0.558$

But deviation of DBP during procedure from baseline is significantly higher among the intravenous group with $t$ $(102.521)=4.535, \mathrm{p}=0.000$

\begin{tabular}{|c|c|c|c|c|c|}
\hline & Groups & Mean & $\begin{array}{c}\text { Std. } \\
\text { Deviation }\end{array}$ & $\mathbf{t}$ & $\mathbf{p}$ \\
\hline $\begin{array}{c}\text { SBP } \\
\text { Difference }\end{array}$ & Intranasal & 8.0625 & 3.98360 & \multirow[t]{2}{*}{1.076} & \multirow[t]{2}{*}{0.285} \\
\hline & Intravenous & 9.1562 & 7.08949 & & \\
\hline $\begin{array}{c}\text { DBP } \\
\text { Difference }\end{array}$ & Intranasal & 5.2812 & 4.29643 & \multirow[t]{2}{*}{4.819} & \multirow[t]{2}{*}{0.000} \\
\hline & Intravenous & 9.5625 & 5.66211 & & \\
\hline & $\begin{array}{r}\text { on of Means } 0 \\
\text { End of Pro }\end{array}$ & Deviat & $\begin{array}{l}n \text { of SBP ar } \\
\text { m Baseline }\end{array}$ & $d D B$ & at the \\
\hline
\end{tabular}

There is no significant difference in the deviation of SBP from baseline to the end of procedure among the two groups with $t$ $(99.176)=1.076, p=0.285$

The deviation of DBP from baseline to the end of procedure was significantly higher among the intravenous group with $t$ $(126)=4.819, p=0.000$

\section{Sedation Scale Used}

\begin{tabular}{|c|c|}
\hline \multicolumn{2}{|c|}{ Cheops Sedation Scale } \\
\hline Score & Inference \\
\hline 4 & Deep Sedation \\
\hline $5-7$ & Adequate Sedation \\
\hline $8-12$ & Moderate Sedation \\
\hline$>13$ & No Sedation (Severe Pain) \\
\hline
\end{tabular}

Comparison of Sedation During Procedure Achieved by The Two Groups

A CHEOPS sedation scale score of $<8$ is taken as adequate sedation during the procedure. 56 children in the intranasal group and 60 children in the intravenous group attained adequate sedation during procedure.

\begin{tabular}{|c|c|c|c|}
\hline & $\begin{array}{c}\text { Adequate } \\
\text { Sedation }\end{array}$ & $\begin{array}{c}\text { Inadequate } \\
\text { Sedation }\end{array}$ & p Value \\
\hline Intranasal & 56 & 8 & \multirow{2}{*}{0.225} \\
\hline Intravenous & 60 & 4 & \\
\cline { 1 - 3 } & \multicolumn{3}{|c}{$\mathrm{X}^{2}$ value: 1.471} \\
\end{tabular}

As the $p$ value is 0.225 , there is no statistically significant difference between the two groups in sedation achieved during procedure.

\begin{tabular}{|c|c|c|c|c|}
\hline & Mean & $\begin{array}{c}\text { Std. } \\
\text { Deviation }\end{array}$ & t Value & p Value \\
\cline { 1 - 3 } Intranasal & 8.19 & 2.39 & \multirow{2}{*}{11.681} & 0.000 \\
\hline Intravenous & 4.09 & 1.46 & & \\
\hline
\end{tabular}

\section{Time Taken to Achieve Adequate Sedation}

It is found that intranasal group has taken a significantly longer time to achieve adequate sedation with $t$ (103.911) $=11.68, \mathrm{p}=0.000$

\section{Time taken for Recovery from Sedation}

The recovery from sedation is also assessed with CHEOPS sedation scale with a score $>7$ suggesting recovery.

\begin{tabular}{|c|c|c|c|c|}
\hline & Mean & $\begin{array}{c}\text { Std. } \\
\text { Deviation }\end{array}$ & t Value & p Value \\
\hline Intranasal & 14.88 & 3.50 & \multirow{2}{*}{3.513} & 0.001 \\
\hline Intravenous & 12.63 & 3.73 & & \\
\hline $\begin{array}{r}\text { The time taken for recovery is significantly longer for } \\
\text { intranasal group with t }(126)=3.513, \mathrm{p}=0.001 .\end{array}$ \\
\hline
\end{tabular}

\section{Adverse Effects Observed}

In the intranasal group 31 children had nasal stuffiness/congestion which is an expected adverse effect of intranasal administration and no other adverse events were noticed. In the intravenous group 2 children had numbness in the hands, 8 children had nausea and one child went into desaturation. No such serious side effects were observed in the intranasal group. 


\section{DISCUSSION}

The study was successfully completed without any major adverse events. This study shows that the children requiring sedation for minor procedures like Lumbar puncture (LP) can be well sedated with intranasal midazolam. Even though LP is a relatively simple and safe procedure to perform, it is frightening for most children and their families.

In a prospective series describing 1459 children receiving lumbar punctures in an emergency department, procedures performed without proper sedation were more likely to be traumatic or unsuccessful than those performed with local anaesthesia.[8] According to the study conducted by Ari Kupietzk et al clinical advantages of midazolam are water soluble, rapid, short acting anticonvulsant, muscle relaxant, anterograde amnesia, clinically inactive metabolites, relatively high margin of safety, reversal agent available and may be administered intranasal.[9] Midazolam produces less post procedure drowsiness and is also characterized by more rapid onset as per the study by James Midtling. ${ }^{[10]}$

Midazolam as intranasal administration has got limitation because of its irritation. Hence the acceptance rate was low as also reported in literature. It may be because of acidic $\mathrm{pH}$. Nasal spray delivery of midazolam makes it less distressing than the common technique of drop instillation as in this study where Metered Atomizing Device (MAD) was used for administration of nasal Midazolam.[11]

In this study the deviation of heart rate from baseline during procedure was significantly more in intravenous group and there was no significant deviation in heart rate in intranasal group. Forster et al.[12] used intravenous midazolam as an induction agent for anaesthesia and stated that midazolam, $0.15 \mathrm{mg} / \mathrm{kg}$ IV over 15 seconds, produces statistically significant increase in pulse rate $(18 \%)$. Kiran, Haripriya et al[13] in their study reported an increasing in pulse rate irrespective of the route of administration of midazolam

In this study the deviation in diastolic blood pressure during and at the end of procedure was significantly more in intravenous group. The deviation in systolic blood pressure in intravenous group was within limits. Intranasal group did not show significant deviation in systolic as well as diastolic blood pressure during and at the end of procedure. Kaufman et al.[14] in their study compared intranasal and intravenous midazolam sedation in a Dental Phobia Clinic and stated that there was no change in blood pressure in both groups of patients. In their study Dixon et al.[15] used sedation for local anaesthesia and compared intravenous midazolam and diazepam and stated that in the intravenous midazolam there was a significant fall in systolic and diastolic blood pressure after satisfactory sedation was obtained. In their study Forster et al.[12] used intra venous midazolam as an induction agent for anaesthesia and stated that in normal persons, midazolam, $0.15 \mathrm{mg} / \mathrm{kg}$ IV over $15 \mathrm{sec}$, produces statistically significant reduction in systolic (5\%) and diastolic (10\%) blood pressure. Acworth JP et al [16] also reported shorter time for sedation in intravenous group.

Nasal stuffiness/congestion was the predominant adverse effect observed in intranasal group which is a minor side effect. No major adverse effects were noted in the intranasal group. Bhakta et al [17] also reported no major side effects with intranasal midazolam.

\section{CONCLUSION}

Intranasal midazolam is safe and effective for procedural sedation in children. Even though quick sedation was achieved by intravenous route, the levels of sedation obtained were comparable between both groups. Heart rate and blood pressure variability were less in intranasal group. No major side effects were noticed in intranasal group. Nasal congestion/stuffiness was the predominant adverse effects noticed in intranasal group which is a minor adverse effect.

\section{REFERENCES}

[1] Hazinski MF. Pain assessment and management in children. 1999;42:1102-25.

[2] Village G. Committee on Psychosocial Aspects of Child and Family Health, 2006;108(3).

[3] Jacob R, Ilamurugu K, Amar N. Paediatric procedural sedation - a review and an update. Indian J Anaesth 2007;51(3):169-75.

[4] Young TE, Neofax MB. A Manual of drugs used in neonatal care. 23rd edn. Montvale, NJ, USA: Thomson Reuters Corporation 2010.

[5] Pacifici GM. Clinical pharmacology of midazolam in neonates and children: effect of disease-a review. Article ID 309342, Int J Pediatr 2014;2014:20. http://www.pubmedcentral.nih.gov

[6] Council O, Council R, Adopted D, et al. Clinical guideline on the elective use of conscious sedation, deep sedation and general anesthesia in pediatric dental patients. Pediatr Dent 1998;(Appendix I):46-51.

[7] Krauss B, Green SM. Procedural sedation and analgesia in children. Lancet 2006;367(9512):766-80.

[8] Fastle RK, Bothner J. Lumbar puncture: Indications, contraindications, technique and complications in children. In: Post T, edr. Uptodate. Waltham, MA: 2017: p. 1-24.

[9] Kupietzky a, Houpt MI. Midazolam: a review of its use for conscious sedation of children. Pediatr Dent 1993;15(4):237-41.

[10] Midtling JI. Midazolam: a new drug for intravenous sedation. Anesth Prog 1987;34(3):87-9.

[11] Gilchrist F, Cairns AM, Leitch JA. The use of intranasal midazolam in the treatment of paediatric dental patients, Anaesthesia 2007;62(12):1262-5.

[12] Forster A, Gardaz JP, Suter PM, et al. I.V. Midazolam as an induction for anesthesia: a study in volunteers. Br J Anaesth 1980;52(9):907-11.

[13] Kiran PM, Haripriya C, Shaik KV, et al. Conscious sedation in minor oral surgery with midazolam iv versus nasal spray a comparative study. Journal of Dental and Craniofacial Research 2017;2(2):15.

[14] Kaufman E, Davidson E, Sheinkman Z, et al. Comparison between intranasal and intravenous midazolam sedation (with or without patient control) in a dental phobia clinic. Journal of Oral \& Maxillofacial Surgery 1994;52(8):840-4.

[15] Dixon J, Power SJ, Grundy EM, et al. Sedation for local anaesthesia: comparison of intravenous midazolam and diazepam. Anaesthesia 1984;39(4):372-6. 
[16] Acworth JP, Purdie D, Clark RC. Intravenous ketamine plus midazolam is superior to intranasal midazolam for emergency paediatric procedural sedation. Emerg Med J 2001;18(1):39-45.
[17] Bhakta P, Ghosh BR, Roy M, et al. Evaluation of intranasal midazolam for pre-anaesthetic sedation in paediatric patients. Indian J Anaesthesia 2007;51(2):111-6. 